\title{
Estimation of critical force of the buckling composite structures using modelling methods
}

\author{
Karol Szklarek ${ }^{1}$, Jakub Gajewski ${ }^{1 *}$, and David Valis $^{2}$ \\ ${ }^{1}$ Lublin University of Technology, Mechanical Engineering Faculty, Nadbystrzycka 36, 20-618 Lublin, Poland \\ ${ }^{2}$ University of Defence in Brno, Faculty of Military Technologies, Kounicova 65, 66210 Brno, Czech Republic
}

\begin{abstract}
The study reported in this paper employed Artificial Neural Networks (ANN) to predict the critical force of the buckling composite structures. The critical force depends upon various factors such as thickness, stacking sequence, etc. These factors have been identified in earlier studies by means of the Finite Elements Method (FEM). The critical force is affected by the above-mentioned factors. Various approaches have been applied in the course of the presented study. Apart from our FEM simulation, the ANN approach has been applied and the results were compared. The main contribution of these two approaches is the estimation of the critical force. The ANN model is trained to predict the critical force for different configurations of input variables.
\end{abstract}

\section{Introduction}

Thin-wall composite structures are now the most desirable constructions in various industries. They are used both in the construction of aircrafts as well as in the construction of bicycles. Thin-walled structures are characterised by very high strength-to-weight and stiffness-to-weight ratios. One of the problems associated with composite structures is the loss of stability. This problem has been widely described in many research publications [1-12].

Accurate knowledge of critical buckling loads is essential for a reliable and light structure design. Composite materials are heterogeneous, anisotropic and difficult to characterise, but are promising in terms of applications. Strength characteristics and properties of the reliability of composite materials are studied in the works $[13,14,16]$. Laminated composites can be adjusted as required, but at the same time their use introduces a high degree of orthotropy, a greater number of design variables, which finally complicate the analysis and design [6].

Currently, numerical methods, such as the finite element method are most often used for buckling analysis of composite structures [1-3, 6, 17]. However, a numerical analysis is not computationally efficient from the design point of view because designing these structures is complicated due to the involvement of a large number of variables. Therefore, nowadays artificial neural networks (ANN) are employed in predicting the critical buckling force.

The ANN modelling is a powerful method because it can be applied to any problem with several variable parameters on the input. The networks can be trained so that they are able to predict results for other variable values based on the results obtained. ANN models have proved to be a great tool for approximation and interpolation in various applications $[4-6,18,19]$. ANNs have been used to match functions and predict various mechanical properties and damage mechanisms in composite materials.

Bezerra et al. [21] used ANN to predict shear stress behaviour for carbon/epoxy and glass/epoxy composites. The authors used a multi-layered model of the neural network. In their studies, they included stress as a function of orientation angle through layers, fibre sample and shear strains, while some other factors such as porosity, number of layers, matrix type and volume fraction of fibres were not investigated. Vassilopoulos et al. [23] used ANN to model the fatigue life of multidirectional composite laminates GFRP. The advantage ANN provided to the authors saved about $50 \%$ of the experimental effort in the whole analysis, compared to conventional methods at the same time maintaining desired accuracy levels. Jiang et al. [22] used the ANN model to predict the mechanical properties and wear of polyamide reinforced short fibres. Polyamide composites were reinforced with short carbon and glass fibres, followed by optimisation of neural networks. The neural network was used to predict mechanical properties and wear as a function of fibre content and testing conditions. Mallela and Upadhyay [6] used artificial neural networks to predict the buckling load of laminated composite stiffened panels subjected to shear stress. In other papers $[4,5,7]$ the authors use ANN to predict the behaviour of isotropic structures during the loss of stability.

In our work, the DOE approach (Design of Experiments) is used to plan data for experimental simulation and generate an input dataset for the ANN model. The database is created using the parametric study and the finite element method. The developed data was

\footnotetext{
* Corresponding author: j.gajewski@pollub.pl
} 
used to train ANNs. Based on the developed studies, several important factors and their impact on critical power have been discussed.

\section{Model based on finite elements method}

The data required for ANN training has been developed using commercial ABAUQS ${ }^{\circledR}$ software. Numerical models created in this program are often confirmed by the experiment and commonly used for calculating the examined issue as well as the materials examined [1-3, $15,20,24-26]$. The object of research is C-profile composite element made of carbon-epoxy tape (Fig. 1).

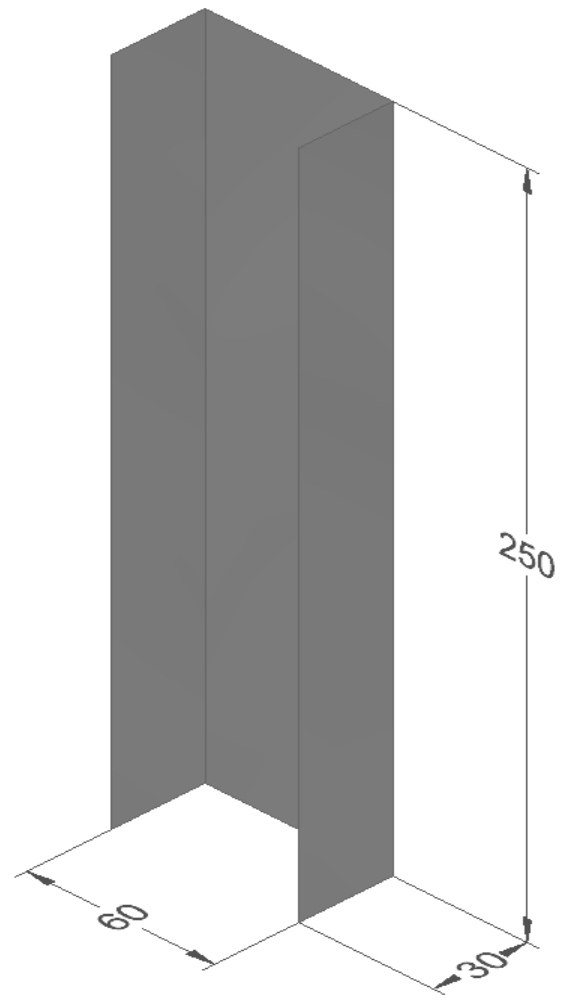

Fig. 1. Tested composite element.

The geometry of the model was discretised with the help of 1,934 S8R finite elements conventional shell S8R with a second-order shape function and reduced integration. The Lanczos solver was used to determine the critical force. The boundary conditions formulated for the numerical model ensured articulated support of the composite element (Fig. 2). The boundary conditions were ensured by applying zero displacements to nodes located on the lower and the upper edge of the crosssection of the composite element, perpendicular to the plane of each wall (displacements $U x=0$ and $U y=0$ ). In addition, the nodes from the bottom end of the column were blocked to prevent the vertical offset of $U z=$ const. The numerical model was subjected to a load applied to the edge of the upper part of the column, which ensured even compression of the column in the axial direction. The section bar consisted of eight layers arranged symmetrically. The thicknesses of a single layer and the compositional properties of a composite are described in the subsequent section of this work.

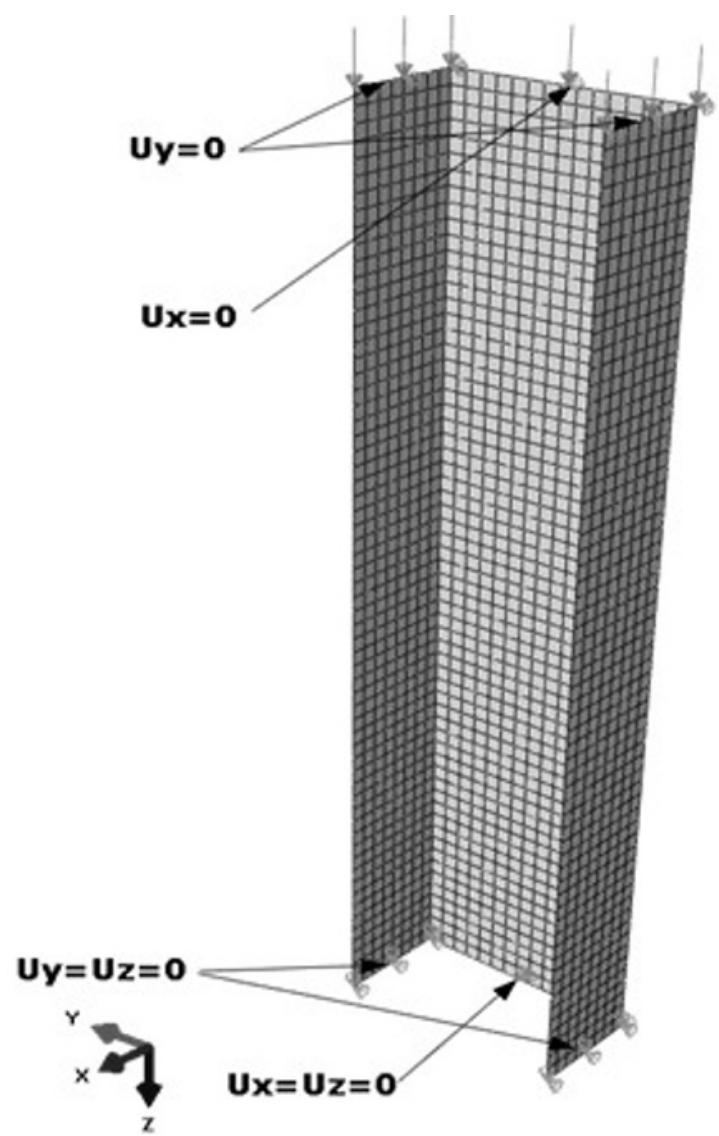

Fig. 2. The boundary conditions of the numerical model.

In the next stage, using the parametric study, the critical force values for different configurations of laminate laying layers were determined. In the parametric study, it was assumed that a single layer of the laminate can be laid in four configurations $[0,90,-45,45]$, the thickness of a single layer was $t=0.105 \mathrm{~mm}$. An exemplary configuration of the fibre arrangement is shown in Fig. 3, while the assumed properties of the laminate in Table 1.

Table 1. Lamina material properties.

\begin{tabular}{|c|c|c|c|}
\hline $\mathbf{E}_{\mathbf{1}}$ [GPa] & $\mathbf{E}_{\mathbf{2}}$ [GPa] & $\mathbf{v}_{\mathbf{1 2}}$ & $\mathbf{G}_{\mathbf{1 2}}=\mathbf{G}_{\mathbf{2 3}}=\mathbf{G}_{\mathbf{1 3}}[\mathbf{G P a}]$ \\
\hline 143.527 & 5.826 & 0.36 & 3.845 \\
\hline
\end{tabular}

The total number of configurations obtained was 256 . The layer systems were then arranged in the descending order of critical force. The values of critical forces for nine fibre configurations numbered $1,32,64,56,128$, 160, 192, 224, 256 are presented in Table 2.

The greatest value of the critical force was obtained for the configuration [-45/45/45 / -45] s, for which the next step was also used. The deformation form for this case is shown in Fig. 4.

The next stage consisted in carrying out parametric studies for various values of mechanical properties of the laminate. The variables at this stage were $\mathrm{E}_{1}$ - the Young's modulus in fibre direction, $\mathrm{E}_{2}-$ the Young's modulus in the transverse direction to the fibres, $v_{12}-$ the Poisson's ratio in the plane of the fibres and $t$ - the thickness of a single layer of the laminate. In this study, no changes to the Kirchhoff module were considered. The range of 
changes in the mechanical properties of the laminate layer and the corresponding intervals are presented in Table 3. The total number of samples obtained was 14,553 .

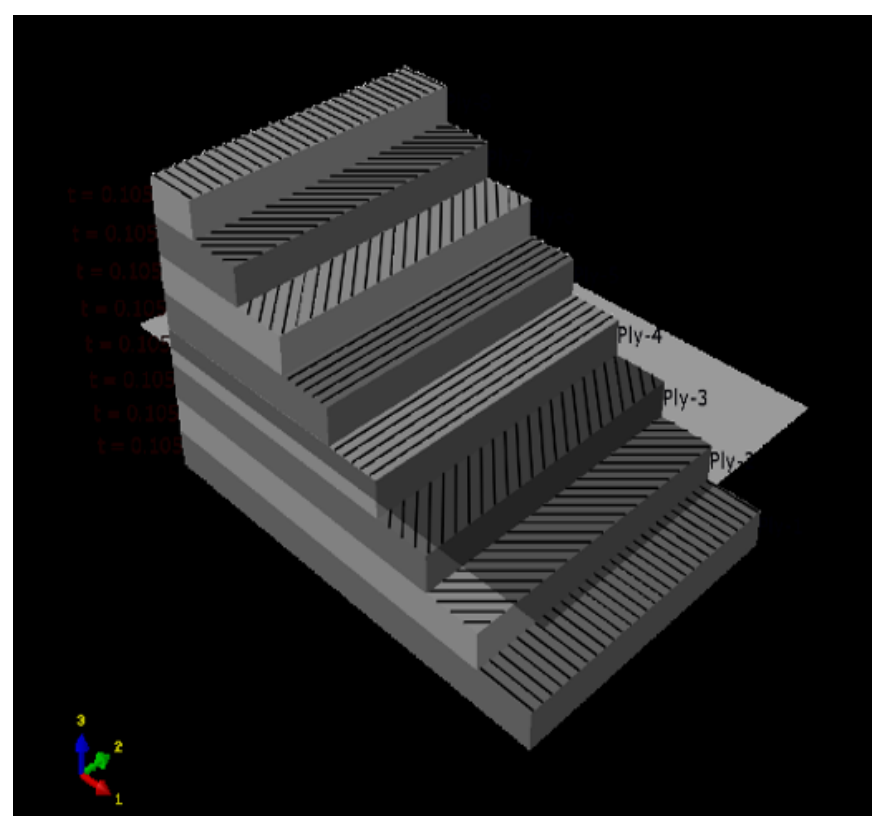

Fig. 3. Example of the configurations of the fibres laminate.

Table 2. Critical force in relation to the stacking sequence.

\begin{tabular}{|c|c|c|}
\hline No. & Stacking sequence & $\begin{array}{c}\text { Critical force } \\
{[\mathbf{N}]}\end{array}$ \\
\hline 1 & {$[-45 / 45 / 45 /-45] \mathrm{s}$} & 3559.8 \\
\hline 32 & {$[45 /-45 / 90 /-45] \mathrm{s}$} & 3022.1 \\
\hline 64 & {$[0 / 45 /-45 /-45] \mathrm{s}$} & 2231.3 \\
\hline 96 & {$[90 / 45 / 0 /-45] \mathrm{s}$} & 2059 \\
\hline 128 & {$[-45 / 90 / 90 / 90] \mathrm{s}$} & 1878.5 \\
\hline 160 & {$[-45 / 0 / 0 / 0] \mathrm{s}$} & 1795.7 \\
\hline 192 & {$[90 /-45 /-45 /-45] \mathrm{s}$} & 1653.4 \\
\hline 224 & {$[0 / 0 /-45 / 45] \mathrm{s}$} & 1390.3 \\
\hline 256 & {$[90 / 90 / 90 /-45] \mathrm{s}$} & 774.39 \\
\hline
\end{tabular}

Table 3. Lamina material properties.

\begin{tabular}{|c|c|c|}
\hline & Value & Interval \\
\hline $\mathrm{E}_{1}[\mathrm{GPa}]$ & $50 .-.210$ & 20 \\
\hline $\mathrm{E}_{2}[\mathrm{GPa}]$ & $6.3-8.6$ & 0.4 \\
\hline$v_{12}$ & $0.25-.0 .35$ & 0.01 \\
\hline $\mathrm{G}_{12}=\mathrm{G}_{13}=\mathrm{G}_{23}[\mathrm{GPa}]$ & 4.670 & \\
\hline $\mathrm{t}[\mathrm{mm}]$ & $0.085-0.125$ & 0.002 \\
\hline
\end{tabular}

The data set was used to teach the ANN by means of the STATISTICA ${ }^{\circledR}$ software. The sampling method was a random method with default subset settings, i.e. a $70 \%$ training set, a test set and a validation set of $15 \%$. An automatic project with an MLP network type was chosen for the method of creating models. The network modelling was performed in 100 repetitions, ten of which with the smallest learning and testing errors were kept. The neural network training was done by means of BFGS (Broyden-Fletcher-Goldfarb-Shanno) method. Parameters of the network are presented in Table 4. The verification of the model's operation on the sample data

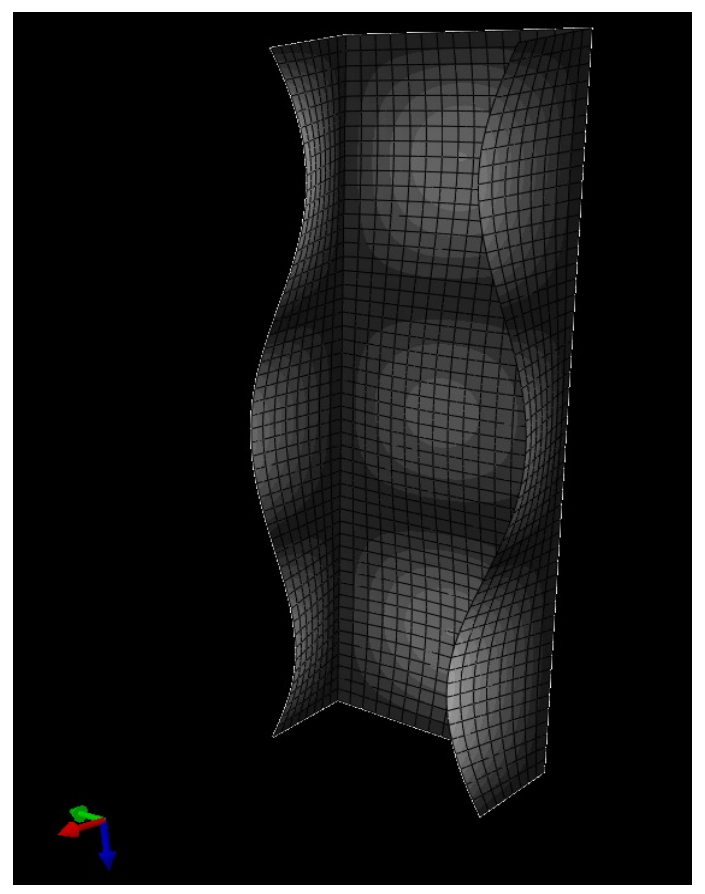

Fig. 4. Visualization of the first form of buckling for [-45/45/45/-45]s configuration.

not used for learning and validating the network amounted to $99 \%$, quality of training, testing and validation exceeded $99.9 \%$

Table 4. MLP 4-5-1 parameters.

\begin{tabular}{|c|c|c|c|c|}
\hline $\begin{array}{c}\text { Error } \\
\text { (training) }\end{array}$ & $\begin{array}{c}\text { Error } \\
\text { (testing) }\end{array}$ & $\begin{array}{c}\text { Error } \\
\text { (validation) }\end{array}$ & $\begin{array}{c}\text { Activat. } \\
\text { (hidden) }\end{array}$ & $\begin{array}{c}\text { Activat. } \\
\text { (output) }\end{array}$ \\
\hline 12.39 & 13.26 & 11.76 & Tanh & Expon. \\
\hline
\end{tabular}

A network MLP 4-5-1 was selected from the results obtained, which had the smallest learning and testing errors. The diagram of this network is shown in Fig. 5.

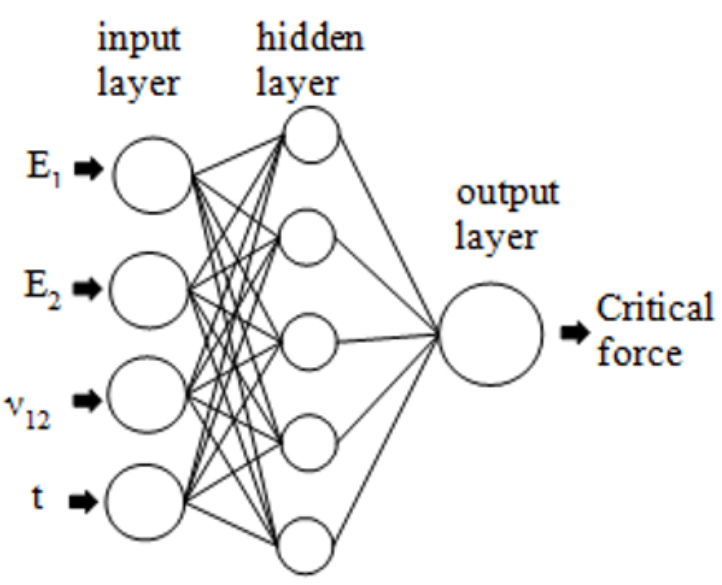

Fig. 5. Artificial Neural Network diagram. 
Table 5 contains the results of the sensitivity analysis of the artificial neural network.

Table 5. Sensitivity analysis.

\begin{tabular}{|c|c|c|c|c|}
\hline NN & $\mathbf{E}_{\mathbf{1}}$ & $\mathbf{t}$ & $\mathbf{E}_{\mathbf{2}}$ & $\mathbf{v}_{\mathbf{1 2}}$ \\
\hline MLP 4-5-1 & 13213 & 12109 & 3.488 & 0.955 \\
\hline
\end{tabular}

The most important factor affecting the value of the buckling critical force is $\mathrm{E}_{1}$ - the Young's modulus in the fibre direction. The second factor, of almost equivalent significance, is the thickness $t$ of a single layer of laminate. Fig. 6 shows the effect of $\mathrm{E}_{1}$ and $t$ on the critical force of buckling.

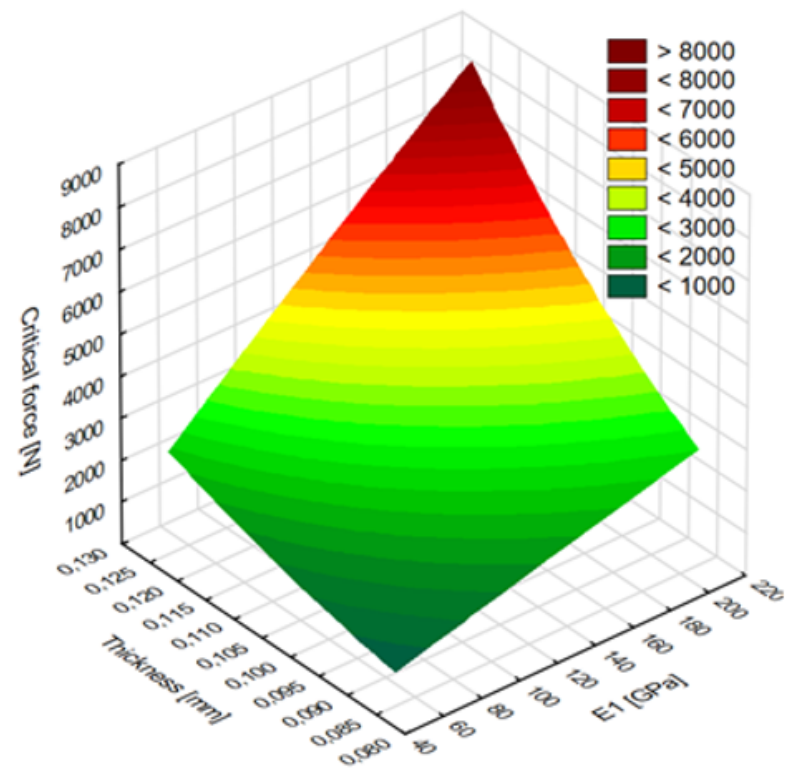

Fig. 6. The effect of Young's modulus and layer thickness on buckling critical force.

As it can be seen in the graph, the value of the critical force increases with the increase of the layer thickness of the laminate and Young's modulus.

Fig. 7 illustrates the effect of the Poisson ratio and the thickness of the laminate layer $t$ on the critical force.

Fig. 6 and Fig. 7 indicate that the change in the thickness of the laminate layer has a highly non-linear effect on the critical force value. The non-linearity increases with the Young's modulus. However, the dependence of the critical force on the Young's modulus is close to linear. The other two parameters according to Table 4 have virtually no effect on the critical force.

\section{Conclusions}

The article attempts to use artificial neural networks to predict the critical force for buckling of a C-shaped composite structure. FEM parametric studies and the DOF method were used to generate input data. The method applied showed that the system of layers for which the critical strength value reaches the maximum is the system [-45 / 45 / 45 / -45] s. The sensitivity analysis showed that the most important parameters are: the Young's modulus in fibre direction and the thickness of a single layer of laminate t. On the other hand, the smallest one, close to zero, has the Poisson's ratio and the Young's modulus in the transverse direction to the fibres. The performance of the obtained neural network reached $99 \%$.

The presented approach can be used to optimise composite structures.

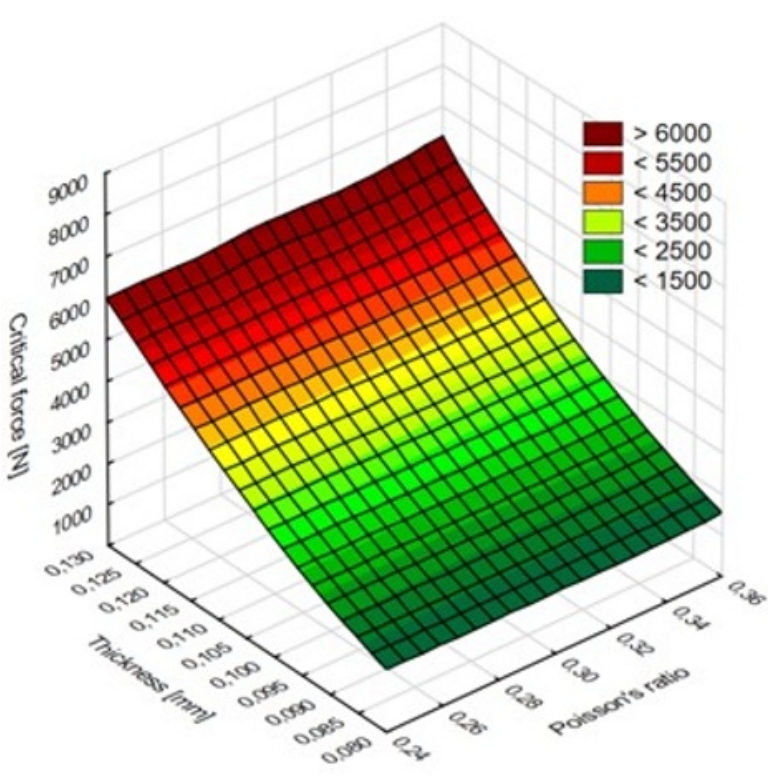

Fig. 7. The effect of Poisson ratio and layer thickness on buckling critical force.

\section{References}

1. P. Różyło, Arch. Mater. Sci. Eng. vol. 84, no. 2, pp. 58-64, (2017)

2. P. Różyło and D. Łukasik, Adv. Sci. Technol. Res. J, vol. 11, no. 1, pp. 194-200, (2017)

3. P. Różyło and K. Wrzesińska, Adv. Sci. Technol. Res. J, vol. 10, no. 31, pp. 199-206, (2016)

4. Z. ul R. Tahir and P. Mandal, Eng. Struct, vol. 152, pp. 843-855, (2017)

5. M. R. Sheidaii and R. Bahraminejad, J. Constructional Steel Res, vol. 70, pp. 71-77, (2012)

6. U. K. Mallela and A. Upadhyay, Thin-Walled Structures, vol. 102, pp. 158-164, (2016)

7. H. Hasanzadehshooiili, A. Lakirouhani, and A. Šapalas, ACME, vol. 12, no. 4, pp. 477-484, (2012)

8. H. Debski, A. Teter, T. Kubiak, and S. Samborski, Compos. Struct., vol. 136, pp. 593-601, (2016)

9. Ö. Namdar and H. Darendeliler, Composites Part B, vol. 120, pp. 143-151, (2017)

10. A. Karrech, M. Elchalakani, M. Attar, and A. C. Seibi, Compos. Struct, vol. 174, pp. 134-141, (2017)

11. K. Falkowicz, ITM Web of Conferences. 15, 07013 (2017)

12. K. Falkowicz, Archives of Civil Engineering. vol. 63, no.4, pp. 161-172 (2017). 
13. K. Hasilová, D. Vališ, Security and Defence Applications. In: 2017 International Conference on Military Technologies (ICMT)., p. 136-141 (2017)

14. D. Vališ, K. Hasilová, Z. Vintr, A. Krzyżak, Safety and Reliability - Theory and Applications. p. 665671 (2017)

15. G. Fedorko, V. Molnar, S. Honus, M. Belusko, M. Tomaskova, Eng. Fail. Anal. 94, pp. 145-156 (2018)

16. D, Vališ, A; Krzyżak, Safety and Reliability of Complex Engineered Systems, p. 2119-2125. (2015)

17. U. K. Mallela and A. Upadhyay, Thin-Walled Structures, vol. 44, no. 3, pp. 354-361, (2006)

18. P. Golewski, J. Gajewski, and T. Sadowski, Arch. Metall. Mater., vol. 62, no. 1, pp. 435-442, (2017)

19. J. Gajewski, P. Golewski, and T. Sadowski, Compos. Struct, vol. 159, pp. 589-599, (2017)

20. H. Dębski and T. Sadowski, Comput. Mater. Sci., vol. 83, pp. 403-411, (2014)
21. E. M. Bezerra, A. C. Ancelotti, L. C. Pardini, J. A. F. F. Rocco, K. Iha, and C. H. C. Ribeiro, Mater. Sci. Eng., A, vol. 464, no. 1-2, pp. 177-185, (2007)

22. Z. Jiang, L. Gyurova, Z. Zhang, K. Friedrich, and A. K. Schlarb, Mater. Des, vol. 29, no. 3, pp. 628-637, (2008)

23. A. P. Vassilopoulos, E. F. Georgopoulos, and V. Dionysopoulos, Int. J. Fatigue, vol. 29, no. 1, pp. 20 29, (2007)

24. M. H. Malik and A. F. M. Arif, Compos. Struct, vol. 101, pp. 290-300, (2013)

25. T. Klepka, H. Dębski, and H. Rydarowski, Polymers, vol. 54, no. 9, pp. 668-672, (2009)

26. J. Gajewski, J. Podgórski, J. Jonak, and Z. Szkudlarek, Comput. Mater. Sci., vol. 43, no. 1, pp. 115-118, (2008) 